THE KAZARGUENE BRIDGE.*

By L. RAMAKERS.

THE road from Verder to Revel, government of Esthonia, Russia, crosses, at the village of Kazarguene, a river of the same name, which, at this point, offer a ford that is passable at low water. During the freshets that occur after somewhat heavy rains, a horseferry establishes a communication between the two
shores; but, in winter, when the ice is not sufficiently shores; but, in winter, when the ice is not sufficiently
strong, and especially during the entire period of the strong, and especially during the entire period of the
breaking up thereof, communication between the two breaking up thereof, communication between the two
shores is completely interrupted. Hence arose the shores is completely interrupted.
necessity of establighing a bridge.

During high water, the discharge of the river is water mark, and, since the banks are low, the country Wemes flooded over a vast area.

Although the river is not navigable, it was decided to give the projected bridge a length of 985 feet, ex-
actly 977 feet between the abutments. As the result of a competition, the work was awarded to the firm of Monicourt \& Egger, general Russian agents for the
Hennebique system, which offered the most favorable

Hennebique

The project presented and approved comprised 13 arch spans, each of 75.5 feet opening. resting upon 12 masonry piers of granite, and one of ordinary concrete; the facings of the two abutments being of gran-
ite. The width of the bridge is 23 feet, including a ite. The width of the bridge is 23 feet, including a
paved roadway 17.5 feet wide and two sidewalks of 2.75 feet each.

The bridge is calculated to carry, in addition to its own weight and that of the paved road, an overcharge of 90 pounds to the square foot. The calculations also provided for the roller.

Each span of the bridge comprises three arches of reinforced concrete. The arches rest upon the masonry of the abutments through the intermedium of a strong sill of reinforced concrete of which the lower part is inclined in a direction at right angles with the thrust, the height of the inclined part of the sill. This latter is so calculated as to distribute the load uniformly over the surface of the abutment. The weight of the abutment and filling is sufficient to assure stability under good conditions, without taking into account the supplementary support given to the rear of the abutment
by the filling in of the road.

The arches rest upon the piers through the intermedium of a horizontal sill of reinforced concrete covering the entire surface of the pier between the arches. A vertical web placed in the axis of the pier and
forming part of the sill cross ties the lower parts of forming part of the sill cross ties the lower parts of
the arches. The surfaces of the sills are so established as to stand a maximum overload of 110 pounds to the as to stand a maximum overload

The surfaces of the foundations of the piers and abutments are so calculated as to give a maximum load of 47 pounds to the square inch upon the ground, this being admissable in view of the fact that the subsoil hard clay mixed with pebbles. The foundations are generally established at this level.

The three reinforced concrete arches of each span have a pitch of $1 / 10$ of the span, say, 7 feet. The
middle arch has a section of 12 inches in height at the key and a width of 10 . The arch continues to spread as far as to the springings, where it has a width of 18 inches. The lateral arches have a constant thickness of 10 inches. The three arches have the same intrados.
Girders of reinforced concrete of $8 \times 10$ inches spaced Girders of reinforced concrete of $8 \times 10$ inches spaced $103 / 4$ feet from axis to axis, are arranged at right angles with the arches. and, with the latter, carry the superstructure of the bridge, which is $43 / 4$ inches in thickness. The cross girders are prolonged externally to the lateral arches and form supports for the sidewalks.. These latter, which are raised above the road, are $43 / 4$ inches in thickness, and are calculated for a

uniformly distributed load of 90 pounds to the
foot. They are paved with slabs of cement.

The side rail is of iron, and is simple and strong. concrete standing in the plane of the aris of reinforced These pillars break the monotony of the line of side rails, which latter are prolonged upon the abutment where large pillars mark the entrance to the bridge.

For half of its length the bridge has two inverse middle span, which is the highest. The water thus middle span, which is the highest. The water thus
flows from the center of the bridge toward the two flows from the center of the bridge toward the two
banks. The paving of the bridge is arranged with the banks. The paving of the bridge is arranged with the
usual convexity in order to direct the water toward usual convexity in order to direct the water toward
the sidewalks. The superficial water flows through the the sidewalks. The superficial water flows through the
superstructure of the bridge through the intermedium superstructure of the bridge through the intermedium
of twelve cast-iron gratings sealed in the concrete. The water of infiltration flows through 26 iron tubes imwater of infiltration flows through 26 iron tubes im-
bedded in the concrete, and the mouth of which is at the level of the top of the concrete of the bridge superstructure.

The concrete designed for the reinforced concret work, and consisting of gravel, sand, and Portland cement, was prepared at the level of the ground in a
vertical concrete mixer actuated by a portable steam engine. At its exit from this the concrete was placed in a car box which, after being filled, was hoisted to the level of the bridge superstructure by means of a
windlass actuated by the engine. At this level the box windlass actuated by the engine. At this level the box
was placed upon the truck of a car and taken to the was placed upon the truck of a car and taken to the
working point. For this purpose, a wooden foot bridge working point. For this purpose, a wooden foot bridge
connected the hoist with the abutment. Upon this foo

* Specially prepared for the ScIENTIFIC AMERICAN SUPPLEMENT. bridge there was laid a track, with a shunt permitting of the running in each direction of the full and empty cars. The railway was afterward prolonged upon the bridge itself in measure as the work progressed. The
superstructure, about twenty-four hours after its completion, received a stratum of sand designed to protect it against the direct action of the sun, and forming a ballast for the car tracks.

The starlings, which are of reinforced concrete, have the form of a carapax covering the front of the piers.
Their edge is inclined at an angle of 45 degrees and Their edge is inclined at an angle of 45 degrees and provided with an angle iron sealed in the concrete and designed to receive the impact of the ice. The removal of the wooden walling of the rubble work, cross-girders and sides of the arches was effected as the work progressed, and the wood was carried to and re-employed in the new spans. As the somewhat high temperature
favored the rapid hardening of the concrete, it was found possible to remove the wood at the end of twenty days and sometimes sooner. The centerings placed directly under the arches were, along with their props, allowed to remain longer in place. The props placed near the piers were removed first in order to permit of the piers.

The presence of the centerings in no wise prevented a moving about on the bridge, which, however, was at materials designed for the paving.

The pitches were observed at the striking of the centerings by means of an amplifying apparatus actuated by a wooden rule fixed to the summit of the tuated by a wooden rule fixed to the summit of the The work was entirely established and calculated ac-
Thes cording to the principles of construction and method of calculation of Engineer Hennebique, of Paris. It is, if not the longest work in reinforced concrete (the if not the longest work in reinforced concrete (th
Simplon aqueduct is 9,840 feet in length, and the BorSimplon aqueduct is 9,840 feet in length, and the Bor-
gone aqueduct 4,590 ), at least the longest reinforced concrete bridge now in existence, so far as we are

It offers an aspect of extreme lightness, and despite its simplicity, not to say absence of decoration, it is by reason of its lines alone, extremely elegant. was tested by the addition of an immovable over charge, and also as to its resistance to shock. The first overcharge test was made by means of a layer of surface of the bridge and sidewalks, the overcharge surface of the bridge and sidewalks, the overcharg covering the second and third span reckoning from the right shore, and having as a value the norma
load of 90 pounds to the square foot. The distortion of the arches were measured by means of wooden rule The maximum pitch ascertained was 1-7,000 of the span. The rules placed in the middle of the arches of spans 1 and 4 indicated a maximum sheer of 0.39 of an inch. In the presence of these remarkable results, the commission raised the overcharge upon half of the third span and distributed it over the second, which remained charged. This latter was thus overcharged one and a half times more than the normal, while the third span was charged asymmetrically upon half of its length. The rules of span No. 1 indicated a maximum sheer of 0.78 of an inch, say $1-4,700$ of the span. This overcharge was left upon the bridge for about fifteen hours, and, after the removal of it, the arches righted tained was less than 1-6,000 of the span.

The tests in the matter of shock consisted in permitting of the fall, from a height of eight feet, of a barrel of 333 pounds to the middle of the panel of superstructure, and then of two barrels of the same weight falling together from the same height. The less than 0.39 of an inch.

\section{ALCOHOL IN GERMANY.}

HOW TANUFACTUBE AN USE.

Consul-General Mason, of Berlin, Germany, in the annexed communication corrects some erroneous impressions that have been created in this country regarding the materials used in Germany for the manu-
facture of alcohol for industrial purposes. The consulgeneral also contributes interesting facts regarding the use of alcohol for motor and industrial purposes. He

From the number of inquiries which have been received recently at this consulate and which seem to have been inspired by press statements published in the United States, it is apparently believed there that alcohol for industrial uses is manufactured in Germany from peat, street garbage, and various other materials, and that the use of alcohol as fuel for motors, especially for automobiles, has been recently begun and is rapi

In reply to all these inquiries it may be said that alcohol is not made on an industrial scale in this country from peat or from garbage of any kind. Aside and medicinal purposes from prunes, grapes, cherries, and other fruits, the great sources of alcohol for industrial and other uses are potatoes, grain, and the molasses derived as a secondary product from the manufacture of beet sugar. From the official statistics of the last year's campaign (September 1, 1903, to which show the total production of alcohol from each of the three materials during the year, in hectoliters of of the three materials during the year, in hectoliters of
26.429 gallons each: Potatoes, $3,045,605$; grain, 692,483 ; beet molasses, 116,211; total, $3,854,299$ hectoliters (101, 823,470 gallons ).

AS A MOTOR AGENT.

In respect to the use of alcohol for motor purposes, the following are the obvious facts:

Several years ago, when the motor vehicle for miliand extraordinary importance, the German governmen became impressed with the necessity of building motors which could be operated with some liquid fuel that could be produced in Germany, in the event that through the chances of war or other cause the supply should be cut off. Alcohol offered the solution of this problem, and all the influence of the Government was exerted to encourage its production and its more ex-
tended use for motor purposes. Prizes were offered for tended use for motor purposes. Prizes were offered for
the best alcohol-driven draft wagons for military and agricultural purposes, and all the great gas-motor builders gave great attention to perfecting engines builders gave great attention to perfecting
specially adapted to the use of alcohol as fuel.

st the same time a powerful organization known as
at a At the same time a powerful organization known as
the Centrale für Spiritus-Verwerthung, with central offices at Berlin and branches throughout the empire was established, and began a systematic, persistent campaign to encourage and extend the use of alcoho for various industrial and economic purposes, especialwere held from year to year, which have been fully were held from year to year, which have been fully the whole apparatus and process of alcohol production from potatoes, corn, and molasses, motors of various purposes, and a vast assortment of alcohol stoves for heating, cooking, ironing, etc., and lamps and chandeliers in endless variety in which alcohol vapor; burned
inside an incandescent mantle, produced a light of high
intensity and cheaper for rural districts of Germany intensity and cheaper for rural dist

The net result of all this systematic effort has been to extend so rapidly the use of alcohol for heating, lighting, and chemical manufacturing purposes that when the drought of last summer reduced somewhat seriously the output of potato alcohol, the previous surhol became too costly for economical use as fuel for motors.

The consequence of all these conditions has been that while the general use of alcohol for industrial purposes, heating, lighting, and a vast range of chemcal and other manufacturing purposes has steadily increased in Germany, the percentage of the whole
product that is used for motor purposes is relatively product that is used for motor purposes is relatively
small and, so far from increasing, is said to be rather diminishing, though to just what extent it would be diminishing, though to just what extent it would be difficult to prove. A few Germans, from patriotic mowagons, motor boats, and farming machinery. A single department store in Berlin, which ordered its equipment of delivery wagons four years ago, during the height "of the alcohol-promotion movement, still conalcohol for driving these wagons, but mixed, for greater alcohol for driving these wagons, but mixed,

efficiency, with about 15 per cent of benzole.
It has been found by elaborate tests that the economy of alcohol as a fuel for gas motors is largely increased by its being carbureted through admixture with a certain percentage of benzole or other product of mineral oil. For a time it was believed that this admix-
ture of benzole could not be safely carried beyond 20 per cent, but more recent experience has shown that a mixture of equal parts of alcohol and benzole can be
used, especially in large motors, with entire safety and economical results. For automobile purposes the usual proportion is now about 30 per cent of benzole or gasoline, but at the present cost of alcohol it can not compete on the score of economy with mineral hyor imported free of duty.

There are now in use in Germany something more than 2,000 stationary or portable alcohol engines, exclusive of the spirit motors used in automobiles. They consumed in the campaign year 1903-4 36,000 hectoto the (951,120 gallons) of denaturated alcohol. Owing overproduction potato crop of 1901 and the consequent grade used for motors could be bought in 1902-3 in any quantity for 15 to 17 cents per gallon, but for reasons hereinbefore stated this price rose in 1904 to 35 marks per hectoliter (about 31.5 cents per gallon), at which figure it became more expensive as motor fuel than gasoline.

Such is substantially the situation in Germany. The manufacture and industrial uses of alcohol were never so great, so important, and so varied as now. This general increase in the campaign year 1903-4, compare with the preceding year, was, according to the annual
report of the Centrale, more than $2,900,000$ gallons. report of the Centrale, more than $2,900,000$ gallons.
But notwithstanding the fact that all the leading German manufacturers of gas engines and motor, vehicles make alcohol motors that are technically successful, the question of price is the controlling consideration, and of the whole $3,854,299$ hectoliters $(101,823,470 \mathrm{ga}$ lons) of spirits produced during the last campaign
year only about 1 per cent was used for motor pur- 